Simpósio: Tópicos avançados para a formação e o desenvolvimento docente para professores dos cursos da área da saúde

\title{
Apresentacão
}

\section{A formação e o desenvolvimento do- cente para os cursos das profissões da saúde: expandindo os horizontes}

\author{
Teacher training and faculty development for health \\ professions education: expanding horizons
}

\author{
Maria Paula Panúncio-Pinto ${ }^{1}$, Luiz Ernesto de Almeida Troncon²
}

\begin{abstract}
"Olhe à sua volta e em qualquer lugar do mundo você irá encontrar salas cheias com estudantes sentados em fila e, à frente, um professor. Este modelo de educação não mudou desde o renascimento e o nascimento da pesquisa científica. Muito cedo na minha carreira eu percebia os primeiros sinais de que algo estava errado nessa maneira de ensinar, mas ignorei isso. Às vezes é difícil encarar a realidade."
\end{abstract}

(tradução livre dos autores do texto de: Mazur E. Farewell, lecture? Science 2009; 323 (5910): 50-51.)

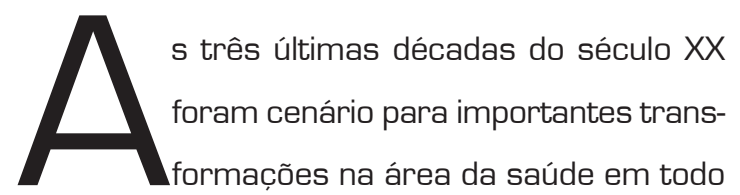

o mundo. Como em qualquer processo de evolução do conhecimento ocorreram reacomodações, reconstruções e mudanças de paradigmas, em consequência dos avanços obtidos por meio da investigação e da comunicação entre distintos campos do saber. ${ }^{1}$

O debate internacional que envolveu, de um lado, o próprio conceito de saúde e a noção de que é um direito do cidadão, bem como os fatores que interfe-
1. Professora Doutora do Departamento de Neurociências e Ciências do Comportamento da Faculdade de Medicina de Ribeirão Preto, Universidade de São Paulo.

2. Professor Titular do Departamento de Clínica Médica da Faculdade de Medicina de Ribeirão Preto, Universidade de São Paulo.
Correspondência:

Profa. Dra. Maria Paula Panúncio-Pinto Departamento de Neurociências e Ciências do Comportamento Hospital das Clínicas da FMRP, $4^{\circ}$ Andar CEP: 14048-900 - Ribeirão Preto / SP mapaula@fmrp.usp.br 
rem no acesso a esse direito* e, de outro a forma de pensar o ensino e a formação de profissionais universitários* * para atuar na atenção à saúde, desencadeou uma reordenação dos sistemas de saúde, com implicações para a formação profissional.

Diante das novas tendências, prevalentes em todo o mundo, que propõem a integração entre a escola e os serviços de saúde, a interdisciplinaridade, o multiprofissionalismo, a intersetorialidade, a diversificação dos cenários de ensino e o compromisso com a realidade, são enormes os desafios que enfrentam diariamente os professores universitários para investir na formação de "cidadãos bem informados, providos de sentido crítico e capazes de analisar os problemas da sociedade, em busca de soluções, assumindo responsabilidade social" ?.

Os professores do Ensino Superior têm sido chamados a ensinar em condições cada dia mais diversas e desafiadoras ${ }^{3}$ e os debates sobre sua formação e desenvolvimento profissional intensificam-se crescentemente.

À Universidade contemporânea coloca-se a contradição entre a concepção de conhecimento construída pela sociedade de mercado e o compromisso com a cidadania, que exige uma formação profissional muito além da instrumentalização para o ingresso no mercado de trabalho ${ }^{4}$.

Tal situação, somada à diversidade do perfil dos estudantes - com necessidades e valores muito variados, coloca em xeque o papel dos professores e as condições de desenvolvimento de suas atividades ${ }^{3}$.

Exige-se do professor a obtenção da titulação acadêmica, cursando a pós-gradução (Mestrado e
Doutorado], onde se dá a consolidação de conhecimentos teóricos e instrumentais sobre seu campo específico. Nas condições atuais de conformação dos programas de pós-graduação acadêmica, decorre que, via de regra, o professor universitário sabe muito da sua área específica, o que não garante sua formação para o ensino: o ensino torna-se ${ }^{4}$ uma decorrência das atividades de pesquisa e da experiência profissional, e a experiência é reconhecida como formação ${ }^{5}$.

Ao reconhecermos a Universidade como lugar de produção do conhecimento e de formação profissional é necessário assumir que é na Universidade que são formados os profissionais que nela trabalham, seja fazendo pesquisa, seja formando profissionais. Paradoxalmente, a ênfase na pesquisa e na produção científica leva a formação de futuros professores apenas na direção da pesquisa, deixando a dimensão pedagógica do ensino e a missão educativa da universidade em segundo plano. De fato, faltam ao professor os fundamentos científicos sobre os elementos constitutivos da atuação docente: organização do currículo, planejamento, preparo das aulas, métodos e estratégias didáticas, avaliação da aprendizagem, peculiaridades da interação professor/aluno. ${ }^{5}$

Neste cenário, não é difícil concluir que instituições e profissionais da Universidade, cuja atividade está permeada de ações pedagógicas, desconhecem a teoria pedagógica e não se aproximam do conhecimento produzido pela Pedagogia. ${ }^{6}$

Discussões sobre educação partem do princípio de que todos sabem do que estão falando. No entanto, quando alguém se torna professor, faz o que seus professores faziam, repetindo o modelo conheci-

\footnotetext{
* A Conferência Internacional Para Cuidados Primários em Saúde, realizada pela Organização Mundial de Saúde-OMS e pelo Fundo das Nações Unidas para a Infância - UNICEF (Alma Ata, 1978) representa o marco que desencadeou uma série de debates materializados em outros documentos internacionais.

** Conferências de Edimburgo (1988, 1993); Conferência Mundial de Educação (UNESCO- Paris 1998).
} 
do, sem parar para pensar sobre "como adultos aprendem" ou "o que" e "como ensinar"7. Somente o reconhecimento de que educação é uma ciência pode promover mudanças nessas práticas. Torna-se, portanto, imperioso reconhecer que a educação é uma área do conhecimento e que a docência é uma atividade profissional específica, e como tal, exige formação específica. 0 ensino é um fenômeno ${ }^{5}$ complexo, realizado por seres humanos e na interação entre eles, podendo ser modificado pela ação intersubjetiva. É necessário reconhecer que transmitir informações é diferente de ensinar, em busca de um conceito de ensinagem, ou de um ensino que resulte em aprendizagem. ${ }^{3,5,7}$

0 desenvolvimento da competência para ensinar pressupõe o domínio de teorias, técnicas e instrumentos de análise. Implica na mobilização de conhecimentos teóricos de educação e de didática, necessários à compreensão do ensino como realidade social. ${ }^{5}$

No contexto da Universidade de São Paulo, a Pró-Reitoria de Graduação vem investindo, desde 2007, no fortalecimento de ações voltadas à valorização do ensino de graduação. Dentre essas ações, destaca-se a constituição do Grupo de Apoio Pedagógico da Universidade de São Paulo (2004, GAP Central), hoje denominada Comissão de Apoio Pedagógico (CAP). As ações desenvolvidas pela CAP investem nos professores, propiciando espaços para ampliar as possibilidades de sua formação pedagógica e para o desenvolvimento profissional docente. Nessa perspectiva destacam-se os Cursos de Pedagogia Universitária e os Seminários de Pedagogia Universitária. Os Cursos de Pedagogia Universitária (2007-2009) tiveram 3 edições com a participação de aproximadamente 500 docentes dos diversos campi da USP. Foram realizados 11 Seminários de Pedagogia Universitária, entre 2007 e 2009, com especialistas em formação de professores.
Considerando, contudo, que a formação de professores tem ou deveria ter início nos programas de pós-graduação, é necessário que estes reconsiderem a sua atuação e revejam quais são as suas propostas para a formação dos estudantes, como futuros docentes da educação superior. Neste sentido, os programas precisam definir e explicitar a sua concepção de docência, que está implicada nessa formação, bem como refletir sobre os modelos de universidade (mercado ou cidadania) e definir qual o perfil de pesquisador-docente se quer formar.

Na Faculdade de Medicina de Ribeirão Preto (FMRP) da Universidade de São Paulo, um grupo de professores, que atualmente conta com 16 componentes ligados a diferentes departamentos e atuando em vários dos cursos de graduação da instituição, engajou-se no Programa "Pró-Ensino na Saúde", criado em âmbito nacional em 2010 por iniciativa da Coordenação de Aperfeiçoamento de Pessoal de Nível Superior (CAPES), por meio das suas áreas de "Programas Estratégicos" e a de "Indução e Inovação". Este grupo vem desenvolvendo diferentes ações para a capacitação e o desenvolvimento profissional na docência, visando os estudantes de pós-graduação que se preparam para a carreira de professores universitários. Este grupo vem também contribuindo para a expansão do conhecimento na área do ensino na saúde, por meio de projetos específicos de investigação científica.

Uma destas aç̃̃es foi a publicação em número recente desta Revista Medicina, de um simpósio intitulado "Tópicos fundamentais para a formação e o desenvolvimento docente para professores dos cursos da área da saúde" contendo 12 textos abordando tópicos básicos destinados à capacitação e o desenvolvimento docente. Estes tópicos fundamentais foram abordados por autores com diferentes trajetórias de forma- 
ção e com experiências diversificadas, mas bem definida nos campos que os respectivos textos abrangem.

Neste número da Revista, este grupo de docentes da FMRP engajados no Programa "Pró-Ensino na Saúde" da CAPES apresenta novo simpósio, composto por coletânea de textos que abrangem tópicos mais avançados relevantes à formação dos professores que atuam no ensino superior profissional na área da saúde. Estes incluem a utilização das tecnologias da informação e da comunicação para o aprendizado eletrônico e a educação à distância, os diferentes métodos e os distintos cenários de ensino, aprendizado e avaliação do estudante, incluindo as simulações e os vários ambientes dos serviços de saúde, os desafios para conseguir a integração curricular, os conceitos e recursos para o treinamento básico e o desenvolvimento do professor, os diferentes componentes do mérito acadêmico (scholarship) em atividades educacionais, a profissionalização docente e a valorização da sua carreira, bem como os fatores ligados ao estudante universitário que representam desafios para a sua educação integral no mundo contemporâneo.

Na elaboração destes textos participaram não só professores da FMRP mas também de outras instituições brasileiras. Como no simpósio anterior, que contou com a colaboração de um autor de Portugal, a presente coletânea inclui a participação de docente de Mendoza, Argentina, de instituição com a qual, o grupo da FMRP mantém colaboração. Como no simpósio anterior, participaram também da elaboração do texto estudantes de pós-graduação, em atividade que representa uma via de mão dupla de contribuições: à formação destes autores e deles à comunidade docente.

Face ao acima exposto, espera-se, portanto, que esta coleção de textos represente contribuição significativa ao preparo do professor e ao incremento da qualidade do trabalho docente nas profissões da área da saúde no Brasil, visando a educação integral do estudante.

\section{Referencias}

1. Kuhn T. A estrutura das revoluções científicas. $12^{\underline{a}}$ Ed. São Paulo: Perspectiva, 2013.

2. Universidade de São Paulo. Biblioteca Virtual de Direitos Humanos. Disponível em http://www.direitoshumanos.usp.br/ index.php/Direito-a-Educa\%C3\%A7\%C3\%A3o/declaracaomundial-sobre-educacao-superior-no-seculo-xxi-visao-eacao.html . [acesso em 13/10/2014]

3. Almeida MI. Formação do Professor para o ensino superior desafios e políticas institucionais. São Paulo: Ed. Cortez, 2012.

4. Goergen P. Formação superior: entre o mercado e a cidadania. In: Pereira, EMA (org.) Universidade e Currículo. Perspectivas de educação geral. Campinas: Mercado de Letras, 2010.

5. Almeida MI, Pimenta SG, Anastasiou, LG. Docência no ensino superior. São Paulo: Ed. Cortez, 2002.

6. Libâneo JC Adeus professor, adeus professora? São Paulo: Cortez, 1998. 